\begin{tabular}{|c|c|}
\hline Title & $\begin{array}{l}\text { A rapid and sensitive LCESI-MSMS method for quantitative analy sis of docetaxel in human plasma and its application } \\
\text { to a pharmacokinetic study. }\end{array}$ \\
\hline Author(s) & $\begin{array}{l}\text { Y amaguchi, Hiroaki; Fujikawa, A suka; Ito, Hajime; Tanaka, Nobuaki; Furugen, Ayako; Miyamori, Kazuaki; } \\
\text { T akahashi, Natsuko; Ogura, Jiro; Kobay ashi, Masaki; Y Y amada, T akehiro; Mano, Nariy asu; Iseki, Ken }\end{array}$ \\
\hline Citation & $\begin{array}{l}\text { Journal of chromatography. B, A nalytical technologies in the biomedical and life sciences, 893-894, 157-161 } \\
\text { https://doi.org/10.1016/.jchromb.2012.02.003 }\end{array}$ \\
\hline Issue Date & $2012-04-15$ \\
\hline Doc URL & http:/hdl. handle.net/2115/50395 \\
\hline Type & article (author version) \\
\hline File Information & Yamaguchi_H_02.pdf \\
\hline
\end{tabular}

Instructions for use 


\section{A rapid and sensitive LC/ESI-MS/MS method for quantitative analysis of docetaxel in human plasma and its application to a pharmacokinetic study}

Hiroaki Yamaguchi ${ }^{\mathrm{a}}$, Asuka Fujikawa ${ }^{\mathrm{a}}$, Hajime Ito ${ }^{\mathrm{a}}$, Nobuaki Tanaka ${ }^{\mathrm{a}}$, Ayako Furugen ${ }^{\mathrm{a}}$, Kazuaki Miyamori ${ }^{\mathrm{a}}$, Natsuko Takahashi ${ }^{\mathrm{b}}$, Jiro Ogura ${ }^{\mathrm{a}}$, Masaki Kobayashi ${ }^{\mathrm{a}}$, Takehiro Yamada $^{\mathrm{c}}$, Nariyasu Mano ${ }^{\mathrm{d}}$, Ken Iseki ${ }^{\mathrm{a},{ }^{*}}$

aLaboratory of Clinical Pharmaceutics \& Therapeutics, Division of Pharmasciences, Faculty of Pharmaceutical Sciences, Hokkaido University, Sapporo 060-0812, Japan ${ }^{\mathrm{b}}$ Graduate School of Medicine, Hokkaido University, Sapporo 060-8638, Japan 'Department of Pharmacy, Hokkaido University Hospital, Sapporo 060-8648, Japan ${ }^{d}$ Department of Pharmaceutical Sciences, Tohoku University Hospital, Sendai 980-8574, Japan

*Corresponding author: Ken Iseki, Ph.D., Laboratory of Clinical Pharmaceutics and Therapeutics, Division of Pharmasciences, Faculty of Pharmaceutical Sciences, Hokkaido University, Kita 12-jo, Nishi 6-chome, Kita-ku, Sapporo 060-0812, Japan.

Phone/FAX: +81-11-706-3770; E-mail: ken-i@pharm.hokudai.ac.jp 


\section{Abstract}

Docetaxel is a taxane family antineoplastic agent widely employed in cancer chemotherapy. We developed a liquid chromatography/tandem mass spectrometry method for the determination of docetaxel in human plasma. Plasma samples were deproteinized by acetonitrile containing internal standard paclitaxel. Chromatographic separation was performed on a TSKgel ODS-100V $3 \mu \mathrm{m}(50 \mathrm{~mm} \times 2.0 \mathrm{~mm}$ i.d. $)$ column using a mobile phase composed of acetonitrile-methanol-water-formic acid (50:5:45:0.1, v/v/v/v). Detection was performed on a triple-quadrupole tandem mass spectrometer with multiple reaction monitoring (MRM) mode via electrospray ionization (ESI) source. This method covered a linearity range of $5-5000 \mathrm{ng} / \mathrm{mL}$ with the lower limit of quantification of $5 \mathrm{ng} / \mathrm{mL}$. The intra-day precision and inter-day precision (R.S.D.) of analysis were less than $6.7 \%$, and the accuracy (R.E.) was within $\pm 9.0 \%$ at the concentrations of $5,20,200$, and $2000 \mathrm{ng} / \mathrm{mL}$. The total run time was $5.0 \mathrm{~min}$. This method was successfully applied for clinical pharmacokinetic investigation.

\section{Keywords}

Docetaxel; LC/ESI-MS/MS; Rapid and sensitive analysis

\section{Abbreviations}

LC/MS/MS, liquid chromatography/tandem mass spectrometry; LLOQ, lower limit of quantification; MRM, multiple reaction monitoring 


\section{Introduction}

Docetaxel is an antineoplastic agent separated from plants of Taxus baccata.

Docetaxel shows its antineoplastic activity by stabilizing microtubules in dividing cells and is used to treat multiple types of tumor including lung, stomach, prostatic, breast, ovary, endometrial, head and neck cancer. Docetaxel often causes severe adverse effects such as neutropenia, which is a dose-limiting factor of docetaxel. There are some reports, which show the relationship between docetaxel pharmacokinetics and adverse effects $[1,2]$. The major elimination pathway of docetaxel is hepatic elimination and over $73 \%$ of docetaxel is excreted into feces. The drug-metabolizing enzyme cytochrome P450 (CYP) 3A4 plays a major role in docetaxel metabolism [3]. Docetaxel is also a substrate of the drug efflux transporter ABCB1 (MDR1, P-glycoprotein), which is normally expressed in hepatocytes, the intestine, renal tubules, and brain $[4,5]$. It has also been reported that docetaxel is a good substrate for the apical drug transporter ABCC2 (multidrug resistance-associated protein 2) in vitro [6]. Yet, little in vivo evidence is currently available on how important $A B C C 2$ actually is in the pharmacokinetics of docetaxel. Thus, the pharmacokinetics of docetaxel is complex and highly individual. It has been suggested that pharmacokinetically guided dose individualization might lead to a better treatment outcome, reducing severe side effects and improving efficacy to the maximum extent possible.

Analytical methods have already been developed to evaluate docetaxel concentration in plasma. Earlier methods used liquid chromatography with ultraviolet detection $[7,8]$. However, these methods have the weakness of limited sensitivity and selectivity. To overcome this weakness, methods using liquid chromatography coupled to mass spectrometry were developed [9-14]. Most assays employ solid-phase 
extraction [9] or liquid-liquid extraction [10-13] as a means of sample pretreatment, requiring evaporation steps. The evaporation procedure is time-consuming and has the risk of exposure to the antineoplastic agent. Recently, occupational exposure of medical staff to antineoplastic agents has become a concern [15-17]. Hou et al. reported the quantitative determination of docetaxel in mouse plasma using protein precipitation for sample pretreatment without evaporation step [14]. However, their method was not sensitive enough for pharmacokinetic analysis of cancer patients because lower limit of quantification (LLOQ) was almost $20 \mathrm{ng} / \mathrm{mL}$. In the present study, we developed a rapid and sensitive LC/MS/MS method for docetaxel quantification in human plasma and the method was applied to the pharmacokinetic study in cancer patients.

\section{Materials and methods}

\subsection{Materials}

Docetaxel and paclitaxel as an internal standard were purchased from Sigma (St. Louis, MO). HPLC-grade acetonitrile, methanol, and formic acid were purchased from Wako (Osaka, Japan).

\subsection{Sample preparation}

A stock solution of docetaxel was prepared in methanol at a concentration of $100 \mu \mathrm{g} / \mathrm{mL}$. A stock solution of internal standard was prepared in acetonitrile at a concentration of $1000 \mathrm{ng} / \mathrm{mL}$. Calibration standards of docetaxel in human plasma were prepared by diluting a plasma working solution at concentrations of 5, 10, 20, 100, 200, 1000, 2000, and $5000 \mathrm{ng} / \mathrm{mL}$. Validation samples of docetaxel in human plasma were prepared by 
diluting a plasma working solution at concentrations of $5,20,200$, and $2000 \mathrm{ng} / \mathrm{mL}$. All solutions were stored at $-30^{\circ} \mathrm{C}$.

\subsection{Sample pretreatment}

We performed deproteination by acetonitrile containing the internal standard. Fifty $\mu \mathrm{L}$ of internal standard in acetonitrile $(1000 \mathrm{ng} / \mathrm{mL})$ was added to fifty $\mu \mathrm{L}$ of plasma sample. The mixture was vortexed and centrifuged at $10,000 \times \mathrm{g}$ for $10 \mathrm{~min}$ at room temperature. The supernatant was filtered with a YMC Duo-Filter (0.2 $\mu \mathrm{m}$, YMC, Tokyo, Japan) and 3 $\mu L$ was injected into the HPLC column.

\subsection{Chromatographic and mass spectrometric conditions}

The HPLC consisted of fully equipped Prominence20A (Shimadzu, Kyoto, Japan). The mobile phase was acetonitrile-methanol-water-formic acid (50:5:45:0.1, v/v/v/v) and was pumped at a flow rate of $0.15 \mathrm{~mL} / \mathrm{min}$. From 2.5 to $5 \mathrm{~min}$, the flow was introduced into the mass spectrometer using a switching valve. For the separation column, we used TSKgel ODS-100V (50 × $2.0 \mathrm{~mm}$ i.d., $3 \mu \mathrm{m}$, TOSOH, Tokyo, Japan). The column temperature was maintained at $40^{\circ} \mathrm{C}$.

Mass spectrometry was carried out on an API3200 triple quadrupole mass spectrometer (Applied Biosystems, Carlsbad, CA). Positive ionization electrospray mass spectrometry was performed. The ionspray voltage was set at $4500 \mathrm{~V}$. The turbospray gas $\left(\mathrm{N}_{2}\right)$ probe was heated at $300^{\circ} \mathrm{C}$. Nitrogen was used as curtain gas, gas 1 and gas 2 , and their flows were set to 20,60 , and 30 units, respectively. Unit mass resolution was set in both mass-resolving quadrupoles Q1 and Q3. The multiple reaction monitoring (MRM) transitions monitored were $\mathrm{m} / \mathrm{z} 808$ to $\mathrm{m} / \mathrm{z} 527$ for docetaxel 
and $\mathrm{m} / \mathrm{z} 854$ to $\mathrm{m} / \mathrm{z} 286$ for internal standard, respectively. The declustering potential was set at $30 \mathrm{~V}$ and the values of the collision energy were 15 and $20 \mathrm{~V}$ for docetaxel and internal standard, respectively. The dwell time was $500 \mathrm{msec}$. Data were collected and processed using Analyst 1.4.2 data collection and integration software (Applied Biosystems, Carlsbad, CA).

\subsection{Method validation}

\subsubsection{Linearity and lower limit of quantification}

For the validation, calibration standards (eight non-zero standards of the analyte, 5, 10, $20,100,200,1000,2000$, and $5000 \mathrm{ng} / \mathrm{mL}$ ) were prepared in control human plasma and analyzed. Linear regression of ratio of the areas of the analyte and internal standard peaks vs the concentration were weighted by $1 / x$ (reciprocal of the concentration). The lower limit of quantification (LLOQ) was defined as the concentration with a signal-to-noise ratio of at least 10 and acceptable precision and accuracy data (R.S.D. and R.E. less than $20 \%$ ).

\subsubsection{Specificity and selectivity}

To determine whether endogenous matrix constituents interfered with the assay, six different batches of blank human plasma samples containing neither analyte nor internal standard (double blank) and samples containing the LLOQ of docetaxel (5 $\mathrm{ng} / \mathrm{mL}$ ) and internal standard were prepared and analyzed.

\subsubsection{Precision and accuracy}

Intra-day $(n=6)$ and inter-day $(n=6)$ precision and accuracy were investigated at four 
different levels, 5 (LLOQ), 20, 200, and $2000 \mathrm{ng} / \mathrm{mL}$. Precision was determined on the basis of coefficient of variation (R.S.D.(\%)), and the accuracy was calculated as (observed concentration-theoretical concentration)/theoretical concentration $\times 100$ (R.E. (\%)).

\subsubsection{Extraction recovery and matrix effect}

The extraction recovery of docetaxel was determined by comparing the peak areas obtained from blank plasma samples spiked with docetaxel before extraction with those from blank plasma samples to which docetaxel was added after extraction. The matrix effect of docetaxel by plasma matrix components was evaluated by comparing the peak areas of an extract of control plasma to which docetaxel had been added after extraction with the peak areas of mobile phase to which the same amount of docetaxel was added. Experiments were performed at three levels, 20, 200 and $2000 \mathrm{ng} / \mathrm{mL}$, in triplicate. The extraction recovery and matrix effect of the internal standard were also evaluated.

\subsubsection{Stability}

The stability of docetaxel in human plasma was examined by analyzing three concentrations $(20,200$ and $2000 \mathrm{ng} / \mathrm{mL})$ in triplicate. These samples were stored at $-30^{\circ} \mathrm{C}$ for 2 months and at ambient temperature for 4 hours to evaluate long-term and short-term stability, respectively. Freeze-thaw stability was tested following three freeze-thaw cycles $\left(-30^{\circ} \mathrm{C}\right.$ to ambient temperature). Stability of the processed samples was assessed by reinjecting the samples after 24 hours in an autosampler $\left(4^{\circ} \mathrm{C}\right)$. 


\subsection{Clinical pharmacokinetics investigation}

Samples for a pharmacokinetic study were collected from 4 head and neck cancer patients treated with docetaxel at Hokkaido University Hospital. Before treatment, patients gave written informed consent as approved by the institutional review board. Docetaxel was administered at a dose of $75 \mathrm{mg} / \mathrm{m}^{2}$ i.v. over $120 \mathrm{~min}$. Whole blood was withdrawn in EDTA tubes at optimal sampling times at the end of infusion, and at 0.5, 1 , $2,3,6,9$, and 24 hours after the end of docetaxel infusion. Samples were immediately stored at $4^{\circ} \mathrm{C}$ and centrifuged at $1,700 \times g$ for $10 \mathrm{~min}$. The resultant plasma was used for analysis. A non-compartmental model was used to estimate the pharmacokinetic parameters. The maximum plasma concentration was defined as the concentration at the end of infusion. The area under the plasma concentration-time curve $\left(\mathrm{AUC}_{0-26 \mathrm{~h}}\right)$ to the last measurable plasma concentration (24 hours after the end of docetaxel infusion) was calculated by the linear trapezoidal rule. Total clearance was calculated from dose divided by $\mathrm{AUC}_{0-26 \mathrm{~h}}$.

\section{Results and discussion}

\subsection{Mass spectrometry}

The positive ion full-scan mass spectra (Q1) of docetaxel and internal standard indicated the presence of the protonated molecular ion $[\mathrm{M}+\mathrm{H}]^{+}$as the predominant ion for each compound with $m / z$ of 808 and 854 , respectively.

The product ion mass spectrum of $[\mathrm{M}+\mathrm{H}]^{+}$at $m / z$ of 808 is shown in Fig. 1A. Product ions appeared at $\mathrm{m} / \mathrm{z}$ of $527,509,327$, and 281 . The proposed fragmentation pattern for docetaxel is presented in Fig. 1A. The product ion at $m / z$ of 527 was the most strongly produced and used for quantitative MRM of docetaxel. 
The protonated molecular ion of the internal standard at $\mathrm{m} / \mathrm{z}$ of 854 was used as a precursor ion to generate the product ion mass spectrum presented in Fig. 1B. The proposed fragmentation pattern for the internal standard is presented in Fig. 1B. For MRM, the fragment at $m / z$ of 286 was used.

\subsection{Chromatography}

Using the mobile phase described in the Materials and methods section, docetaxel and internal standard were perfectly separated. The retention time of docetaxel was $3.6 \mathrm{~min}$ and that of internal standard was $4.2 \mathrm{~min}$. Total LC run time was $5 \mathrm{~min}$. From 0 to 2.5 min, LC flow was diverted to waste, we thereby avoided contamination of ion source by impurities such as salts in plasma sample.

\subsection{Method validation}

\subsubsection{Linearity and lower limit of quantification}

The present method covered a linearity range of 5 to $5000 \mathrm{ng} / \mathrm{mL}$ of concentration in plasma with a weighting by $1 / x$. The correlation coefficient $(r)$ was $>0.999$. A typical standard curve was $y=0.00207 x+0.0251$. The LLOQ for docetaxel was $5 \mathrm{ng} / \mathrm{mL}$ in plasma. The present method can determine docetaxel concentrations in plasma samples until at least $24 \mathrm{~h}$ after 1 - to $2-\mathrm{h}$ infusion at a dose of $75-100 \mathrm{mg} / \mathrm{m}^{2}[11,18]$. The method is sensitive enough to evaluate the pharmacokinetics of docetaxel in cancer patients.

\subsubsection{Specificity and selectivity}

We evaluated the specificity and selectivity of the method. A representative MRM 
chromatogram of blank human plasma and chromatograms of LLOQ of docetaxel and the internal standard spiked in human plasma are shown in Fig. 2 (A), (B), and (C), respectively. There was no significant interference from endogenous plasma constituents at retention times of docetaxel and the internal standard.

\subsubsection{Precision and accuracy}

Intra-day $(n=6)$ and inter-day $(n=6)$ accuracy and precision were investigated at four different levels, 5 (LLOQ), 20, 200, and $2000 \mathrm{ng} / \mathrm{mL}$. The results are summarized in Table 1. The intra- and inter-day accuracy (R.E. (\%)) was at most within $\pm 9.0 \%$ for all concentrations. The intra- and inter-day precision (R.S.D. (\%)) was less than $6.7 \%$ for all concentrations. These results suggest that the present method can accurately and reproducibly measure docetaxel in human plasma.

\subsubsection{Extraction recovery and matrix effect}

The extraction recoveries of docetaxel from human plasma were $82.3 \pm 1.9 \%, 77.6 \pm$ $9.2 \%$ and $89.4 \pm 6.0 \%$ at concentrations of 20,200 and $2000 \mathrm{ng} / \mathrm{mL}$, respectively. The extraction recovery of the internal standard was $91.8 \pm 3.1 \%$.

A matrix effect of docetaxel by plasma matrix components was not observed (97.8 $\pm 5.6 \%, 99.0 \pm 7.6 \%$ and $95.4 \pm 4.8 \%$ at concentrations of 20,200 and $2000 \mathrm{ng} / \mathrm{mL}$, respectively). The matrix effect of internal standard was $108.1 \pm 4.9 \%$ at a concentration of $1000 \mathrm{ng} / \mathrm{mL}$.

\subsubsection{Stability}

The stabilities of docetaxel in plasma under different conditions were evaluated (Table 
2). No significant degradation was observed for 2 months at $-30^{\circ} \mathrm{C}$ (long-term stability), for $4 \mathrm{hr}$ at ambient temperature (short-term stability), and during three freeze/thaw cycles. Post-extraction samples kept in the autosampler at $4^{\circ} \mathrm{C}$ for $24 \mathrm{~h}$ were also stable.

\subsection{Clinical pharmacokinetics investigation}

The suitability of the developed method for clinical use was demonstrated by the determination of plasma docetaxel levels from 4 head and neck cancer patients treated with docetaxel at a dose of $75 \mathrm{mg} / \mathrm{m}^{2}$. The MRM chromatogram of docetaxel in plasma taken from a patient at the end of docetaxel infusion is shown in Fig. 2 (D). No interfering peak was observed, and this analytical method was successfully applied for the determination of docetaxel in patient plasma. The plasma concentration-time profiles of a 2-h intravenous infusion of docetaxel at a dose of $75 \mathrm{mg} / \mathrm{m}^{2}$ is shown in Fig. 3. The maximum plasma concentration was $2035 \pm 477 \mathrm{ng} / \mathrm{mL}$. Plasma concentrations of docetaxel at $24 \mathrm{~h}$ after the end of the infusion were above LLOQ in all patients. The AUC $_{0-26 \mathrm{~h}}$ value was $3313 \pm 873 \mathrm{ng} \mathrm{h} / \mathrm{mL}$, and the total clearance of docetaxel was 23.9 $\pm 6.3 \mathrm{~L} / \mathrm{h} / \mathrm{m}^{2}$. These data indicated in the present study were comparable with previous reports [2,18], and strongly suggest that our method is useful for clinical pharmacokinetic analysis.

\section{Conclusion}

A rapid and sensitive LC/MS/MS assay was developed for the quantification of docetaxel in human plasma. The sample preparation of the established method is one-step protein precipitation without evaporation step, meaning that not only it needs 
simple technique but also the exposure of antineoplastic drugs could be avoidable. The validation results showed that an accurate, reproducible and selective assay was achieved. This method can be applied for the clinical pharmacokinetics study of docetaxel in cancer patients.

\section{Acknowledgements}

The authors thank staff members of the Department of Medical Oncology, Hokkaido University Graduate School of Medicine for donating blood samples of cancer patients.

\section{References}

[1] R. Bruno, D. Hille, A. Riva, N. Vivier, W.W. ten Bokkel Huinnink, A.T. van Oosterom, S.B. Kaye, J. Verweij, F.V. Fossella, V. Valero, J.R. Rigas, A.D. Seidman, B. Chevallier, P. Fumoleau, H.A. Burris, P.M. Ravdin, L.B. Sheiner. J, Clin. Oncol. 16 (1998) 187.

[2] S.D. Baker, A. Sparreboom, J. Verweij, Clin. Pharmacokinet. 45 (2006) 235.

[3] I. Royer, B. Monsarrat, M. Sonnier, M. Wright, T. Cresteil, Cancer Res. 56 (1996) 58.

[4] M.T. Huisman, A.A. Chhatta, O. van Tellingen, J.H. Beijnen, A.H. Schinkel, Int J Cancer 116 (2005) 824.

[5] G. Bradley, V. Ling, Cancer Metastasis Rev. 13 (1994) 223.

[6] R.A. van Waterschoot, J.S. Lagas, E. Wagenaar, H. Rosing, J.H. Beijnen, A.H. Schinkel, Int. J. Cancer 127 (2010) 2959.

[7] L. Zufía López, A. Aldaz Pastor, J.M. Aramendia Beitia, J. Arrobas Velilla, J. Giraldez Deiró, Ther. Drug Monit. 28 (2006) 199.

[8] S. Bermingham, R. O'Connor, F. Regan, G.P. McMahon. J. Sep. Sci. 2010, 33, 1571. 
[9] R.A. Parise, R.K. Ramanathan, W.C. Zamboni, M.J. Egorin, J. Chromatogr. B Analyt. Technol. Biomed. Life Sci. 783 (2003) 231.

[10] K.A. Mortier, V. Renard, A.G. Verstraete, A. Van Gussem, S. Van Belle, W.E. Lambert, Anal. Chem. 77 (2005) 4677.

[11] L.Z. Wang, B.C. Goh, M.E. Grigg, S.C. Lee, Y.M. Khoo, H.S. Lee, Rapid Commun.Mass Spectrom. 17 (2003) 1548.

[12] J. Guitton, S. Cohen, B. Vjgnal, J.P. Droz, M. Guilaumont, M. Manchon, G. Freyer, Rapid Commun. Mass Spectrom. 19 (2005) 2419.

[13] Q. Huang, G.J. Wang, J.G. Sun, X.L. Hu, Y.H. Lu, Q. Zhang, Rapid Commun. Mass Spectrom. 21 (2007) 1009.

[14] W. Hou, J.W. Watters, H.L. McLeod, J. Chromatogr. B Analyt. Technol. Biomed. Life Sci. 804 (2004) 263.

[15] T.H. Connor, D.G. DeBord, J.R. Pretty, M.S. Oliver, T.S. Roth, P.S. Lees, E.F. Jr. Krieg, B. Rogers, C.P. Escalante, C.A. Toennis, J.C. Clark, B.C. Johnson, M.A. McDiarmid, J. Occup. Environ. Med. 52 (2010) 1019.

[16] P.A. Ratner, J.J. Spinelli, K. Beking, M. Lorenzi, Y. Chow, K. Teschke, N.D. Le, R.P. Gallagher, H. Dimich-Ward, BMC Nurs. 9 (2010) 15.

[17] C. Sottani, B. Porro, M. Comelli, M. Imbriani, C. Minoia. J, Chromatogr. B Anal. Technol. Biomed. Life Sci. 878 (2010) 2593.

[18] S. J. Clarke, L.P. Rivory, Clin. Pharmacokinet. 36 (1999) 99. 


\section{Figure legends}

Figure 1 Product ion mass spectra of docetaxel $(A)$ and internal standard $(B)$ and proposed fragmentation patterns. Ac, acetyl; Ph, phenyl.

Figure 2 Representative MRM chromatograms of blank plasma (A), LLOQ of docetaxel (5 ng/mL) (B), and internal standard (C) spiked in human plasma, and the chromatogram of docetaxel in plasma taken from a patient at the end of docetaxel infusion (D).

Figure 3 Plasma concentration-time curves of docetaxel in head and neck cancer patients after 2-h infusion at a dose of $75 \mathrm{mg} / \mathrm{m}^{2}$. 
Table 1 Precision and accuracy of the quantification of docetaxel in human plasma

\begin{tabular}{|c|c|c|c|c|c|c|c|}
\hline \multirow{2}{*}{ Analyte } & \multirow{2}{*}{$\begin{array}{l}\text { Concentration } \\
(\mathrm{ng} / \mathrm{mL})\end{array}$} & \multicolumn{3}{|c|}{ Intra-day $(n=6)$} & \multicolumn{3}{|c|}{ Inter-day $(n=6)$} \\
\hline & & Found (ng/mL) & R.S.D. (\%) & R.E. (\%) & Found (ng/mL) & R.S.D. (\%) & R.E. (\%) \\
\hline \multirow{4}{*}{ Docetaxel } & 5 & $4.98 \pm 0.29$ & 5.9 & -0.3 & $4.83 \pm 0.32$ & 6.7 & -3.4 \\
\hline & 20 & $19.72 \pm 0.59$ & 3.0 & -1.4 & $20.00 \pm 0.78$ & 3.9 & 0.0 \\
\hline & 200 & $211.8 \pm 11.8$ & 5.6 & 5.9 & $218.0 \pm 5.9$ & 2.7 & 9.0 \\
\hline & 2000 & $2008 \pm 78$ & 3.9 & 0.4 & $2033 \pm 42$ & 2.1 & 1.7 \\
\hline
\end{tabular}


Table 2 Stability of docetaxel in human plasma

\begin{tabular}{lccc}
\hline \multirow{2}{*}{ Stability } & \multicolumn{3}{c}{ Remaining (\%) } \\
\cline { 2 - 4 } & $20 \mathrm{ng} / \mathrm{mL}$ & $200 \mathrm{ng} / \mathrm{mL}$ & $2000 \mathrm{ng} / \mathrm{mL}$ \\
\hline Long-term stability & $101.4 \pm 3.8$ & $104.3 \pm 2.9$ & $98.9 \pm 3.0$ \\
Short-term stability & $97.8 \pm 4.7$ & $94.7 \pm 1.2$ & $94.1 \pm 1.1$ \\
Freeze-thaw stability & $100.3 \pm 1.1$ & $105.3 \pm 5.4$ & $101.4 \pm 1.3$ \\
Processed sample stability & $101.7 \pm 4.9$ & $94.7 \pm 5.2$ & $101.3 \pm 6.0$ \\
\hline
\end{tabular}


Figure 1
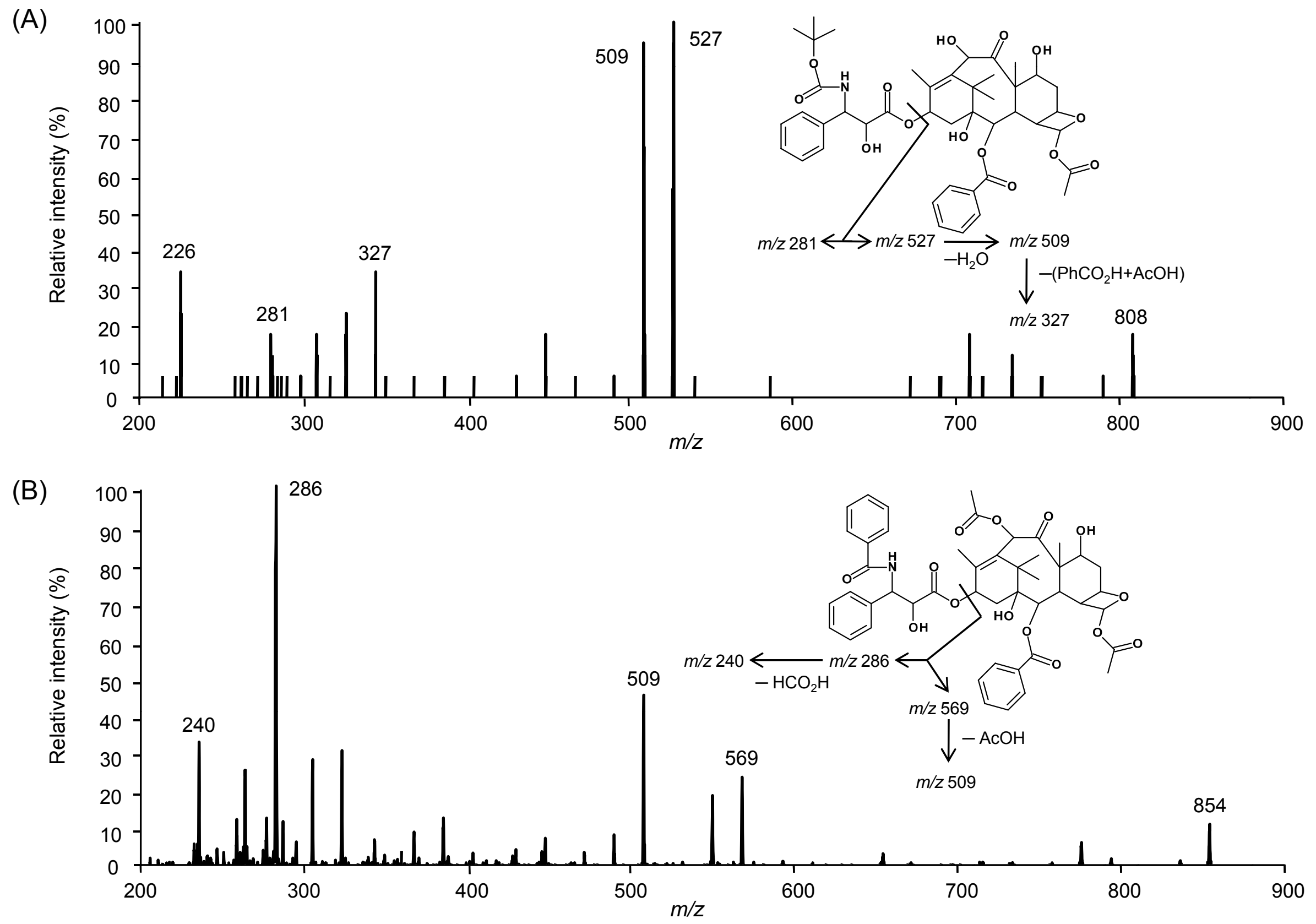
Figure 2

(A)

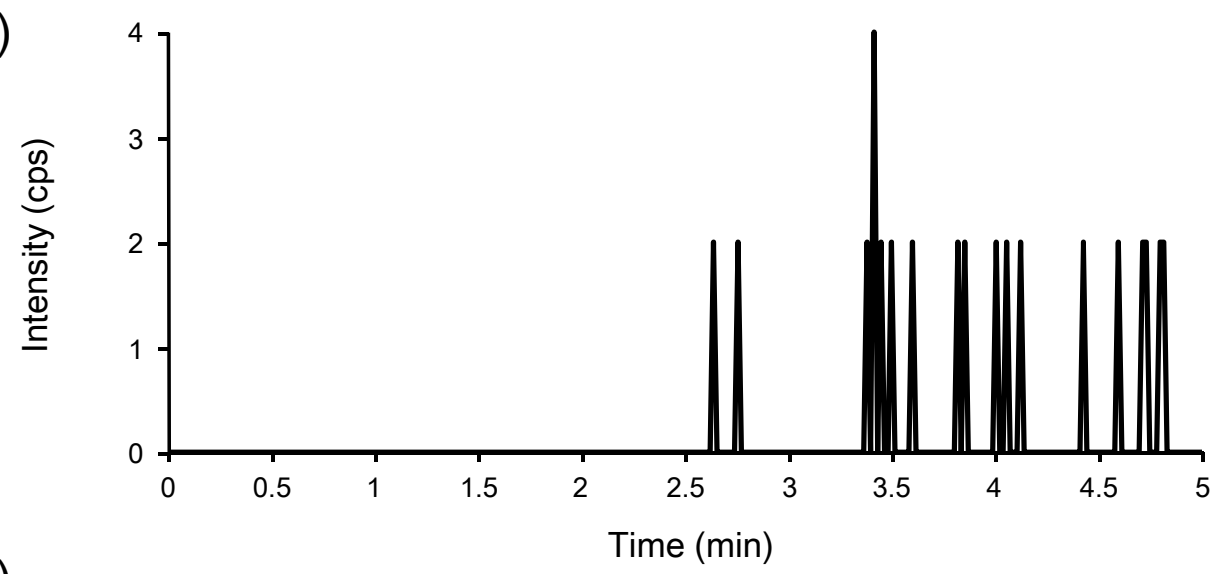

(B)

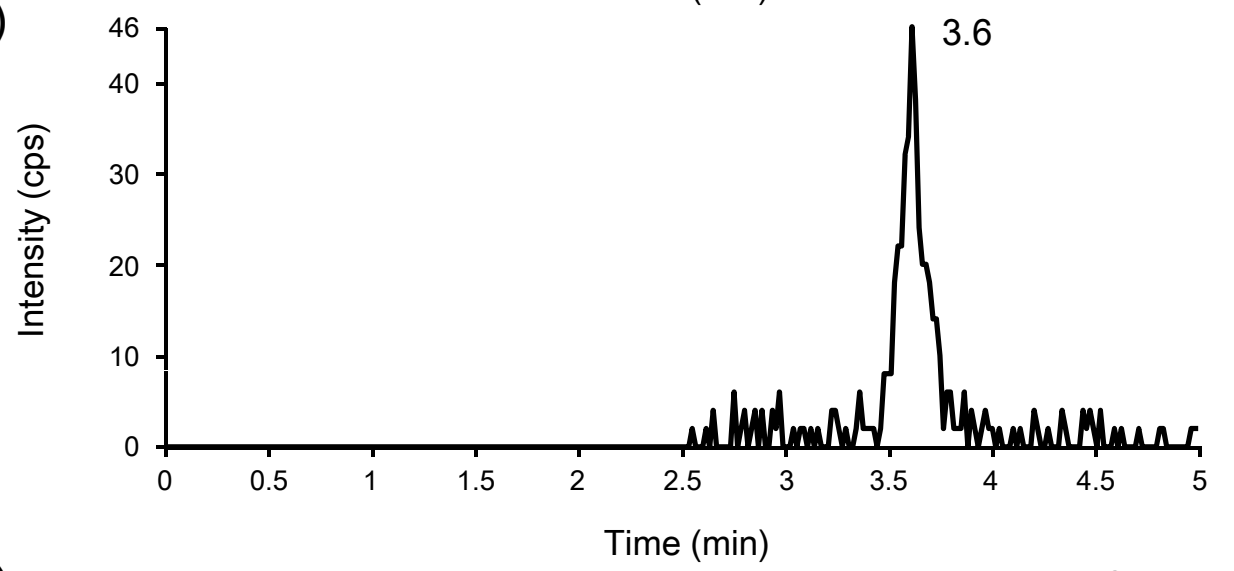

(C)
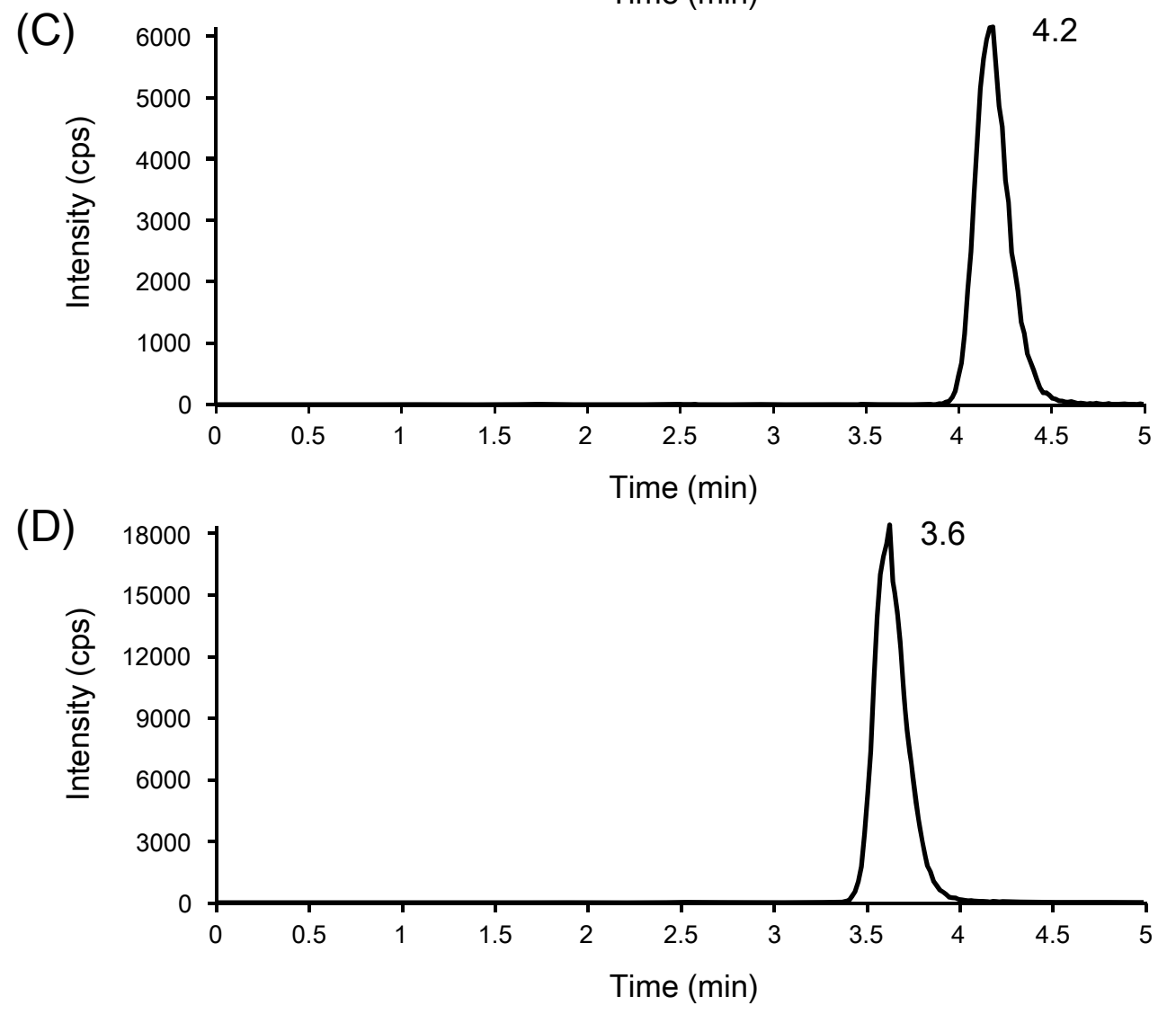
Figure 3

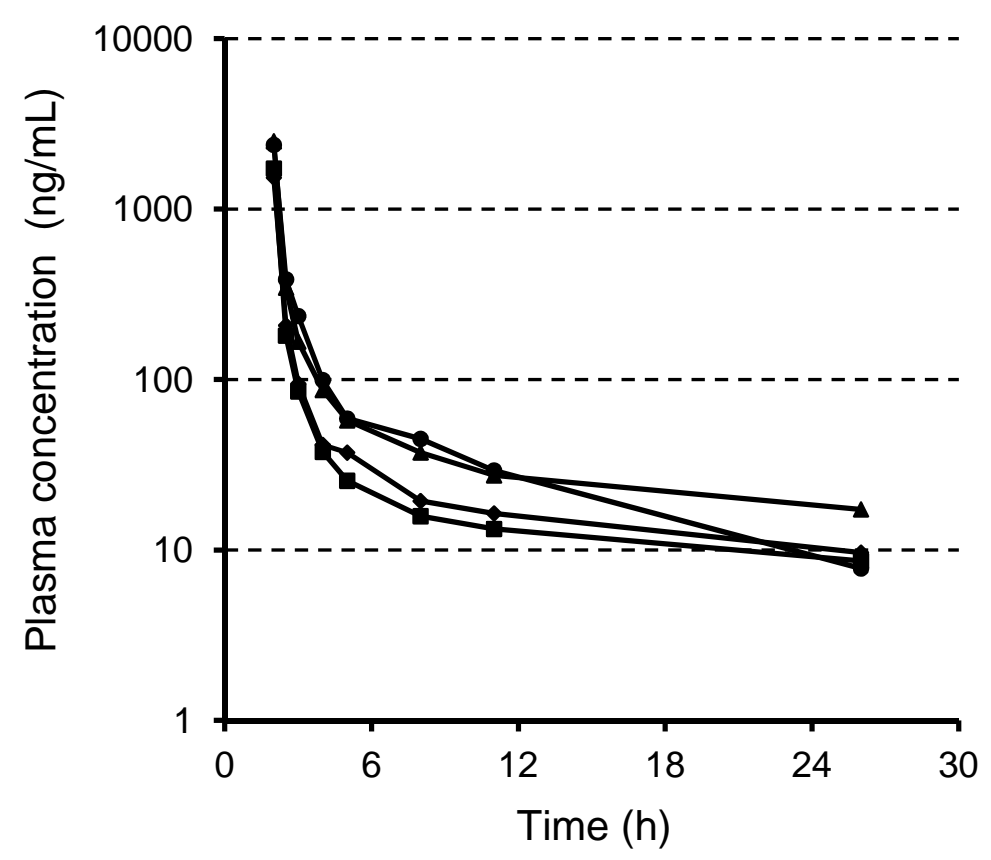

